\title{
RECURSOS GENÉRICOS DE LA NOVELA DE CIENCIA FICCIÓN DE PEDRO SALINAS
}

\author{
Fernando Ángel Moreno \\ Universidad Complutense de Madrid
}

A menudo se cita la fecha de la caída del lanzamiento de la bomba de Hiroshima, seis de agosto de 1945, como el comienzo simbólico de la posmodernidad. Al fin y al cabo, ninguna disciplina filosófica o religiosa aporta una justificación teleológica a la consiguiente posibilidad de exterminio de toda la raza humana. Tras este hecho, uno de nuestros más importantes poetas cscribía las siguientes líneas:

Es el coronamiento de la época más estúpida de la historia humana. ¡Y qué comentarios los de alguna gente! Demuestran que la historia estaba a punto para que la bomba naciera. [... Se inaugura la era del terrorismo mundial. Ahora ya vivimos bajo una amenaza vaga, difusa, superior a todos los temores de antes. ${ }^{1}$

Las razones que a menudo se dan para la instauración del género de la ciencia ficción en este periodo de la historia coinciden con este sentir de Salinas compartido por autores como el propio Isaac Asimov:

La primera indicación clara de que era la gente que escribía y leía ciencia ficción la que vivía el mundo real, y todos los demás los que vivían en el reino de la fantasía, llegó el 6 de agosto de 1945, cuando el mundo descubrió que una bomba atómica había explotado sobre Hiroshima. ${ }^{2}$

Por razones que sólo pueden vincularse bien con el desconocimiento, bien con el desprecio por el género, la novela que he estudiado, La bomba increíble: una fabulación, no suele ser catalogada dentro de la literatura de ciencia ficción, ni siquiera ha sido considerada

1.- El autor del prólogo a la novela, Andrés Soria Olmedo, cita esta declaración de Salinas sin indicar la procedencia de la misma. SALINAS, Pedro (1950), La bomba increfble: fabulación, Madrid, Viamonte, 1997, p. 14.

2.- ASIMOV, Isaac (1981), Sobre la ciencia ficción, Barcelona: Edhasa, 1986, p. 120. 


\section{RECURSOS GENÉRICOS DE LA NOVELA DE CIENCIA FICCIÓN}

novela especulativa ${ }^{3}$. Incluso la edición de Viamonte evita la etiqueta de «ciencia ficción» en cualquier elemento paratextual de la publicación ${ }^{4}$. El prologuista -como otros estudiosos-, en el colmo del eufemismo, las relaciona con conocidísimas novelas de ciencia ficción, como 1984, de George Orwell, o Un mundo feliz, de Aldous Huxley, pero bajo el menos polémico término: romans d'anticipation, que queda mucho más engolado. Este esnobismo sólo puede justificarse por ignorancia o por miedo a desmerecer el nombre del poeta o bajar las ventas de la obra 5 .

No entraremos en una apología que no viene al caso en estas líneas y que ya se está realizando en otros lugares ${ }^{6}$. Por otra parte, tanto el prejuicio como la ignorancia respecto al género ya han sido denunciados en numerosas ocasiones?

Puede observarse incluso en los análisis de críticos de reconocida trayectoria, que han analizado la novela y han dado rodeo tras rodeo sin llegar a señalar el género al que pertenece.

La bomba incré́ble no es precisamente «novela», aunque desde luego sea obra novelesca. El autor la denomina fabulación, y el término parece adecuado. Es una historia imaginaria adscrita al género llamado «anticipaciones», muy en boga actualmente para responder a la ansiedad colectiva, afanosa de levantar siquiera una punta del velo ocultador del futuro. La corriente de profetismo, generalmente pesimista y desesperanzada, produjo una obra maestra: 1984, de George Orwell. La narración de Pedro Salinas no podía tener, ni tiene apenas, puntos en contacto con esta y otras obras análogas. Es una anticipación, ciertamente, pero sin el acento patético que Orwell o Arthur Koestler imprimieron a sus ficciones futurizantes. Más cerca está el huxlcyano ;Dichoso mundo nuevo! [sic] [se refiere a Un mundo feliz, de Aldous Huxley]. ${ }^{8}$

Sin embargo, empiezan ya a aparecer estudios más serios y rigurosos que revelan dicho género como una herramienta retórica de ilimitadas posibilidades poéticas y de magníficas realizaciones

3.- Es chocante cómo una gran parte del estudio de Pardo Pastor analiza la «genialidad» de Salinas, al considerar que ha tratado originalmente un problema de su tiempo mediante una traslación al futuro. En esta línea, muchas páginas de su estudio más que un análisis sobre La bomba increible en realidad son -sin que el autor lo mencione en ningún momento-una explicación de los funcionamientos ya conocidos del género de la ciencia ficción. PARDO PASTOR, Jordi (2003), "La idea del 'Ser' en La bomba increíble, de Pedro Salinas" en Crítica Hispánica, vol. 25, núms. 1-2, 2003, pp. 133-138. El estudio, por otra parte, es muy interesante por las vinculaciones filosóficas implicadas. Coincido, por otra parte, con la consideración de que nos encontramos ante una magnífica obra muy poco conocida y de hallazgos poéticos muy interesantes.

4.- En la contraportada, los editores escriben: «...puede ser leída como una impresionante parábola, no exenta de ironía y sentido del humor, sobre el destino de la humanidad en un mundo en el que todos los valores parecen trastocados. En ese mundo mecaniscista $\mathrm{e}$ hiperracionalizado...», pero no se habla de ciencia ficción.

5.- No es el primer caso de una novela de un importante escritor español en cuya edición se evita como lepra el término «ciencia ficción». Recordemos el caso de: TORRENTE BALLESTER, Gonzalo (1984), Quizá nos lleve el viento al infinito, Barcelona: Plaza\&Janés, novela de robots sobre cuyo tema no aparece ninguna referencia en espacio alguno de la edición, ni del género al que pertenece la novela. Para la crítica de este hecho: DíEZ, Julián (ed.) (2003), Antología de la ciencia ficción española: 1982-2002, Barcelona: Minotauro, p. 22.

6.- MORENO SERRANO, Fernando Ángel (2007), "Notas para una historia de la ciencia ficción en España" en Dicenda. Cuadernos de Filología Hispánica, $\mathrm{n}^{\circ}$ 27, pp. 125-126 y MORENO SERRANO, Fernando Ángel (2006): La ciencia ficción en España (1950-2000), Tesis inédita, Madrid: Universidad Complutense de Madrid.

7.- AMIS, Kingsley (1961). El universo de la ciencia ficción. Madrid: Ciencia Nueva, 1966; FERRERAS, Juan Ignacio (1972). La novela de ciencia ficción, Madrid, Siglo XXI; LEWIS, C.S. (2004) "Sobre la ciencia-ficción", en De este y otros mundos: Ensayos sobre literatura fantástica, Barcelona: Alba Editorial, pp. 93-110.

8.- GULLÓN, Ricardo (1951), "Pedro Salinas, novelista", en G. DE LA CONCHA, Víctor (ed.) (1984), Barcelona: Crítica, pp. 570-571. 


\section{FERNANDO ÁNGEL MORENO}

con un sitio ya destacado dentro de la historia de la literatura?.

Pues bien, como veremos la adscripción de la novela al género de la ciencia ficción e incluso su estrecha vinculación, por otro lado, con la literatura fantástica representan cuestiones de extrema importancia para el análisis de esta novela que, por cierto, para el amigo del autor, Jorge Guillén, cra una gran novela:

Ya vive en mi recuerdo, como una obra "clásica»: La bomba incréble. ¡Qué incréble prodigio! Tu «vena» de satírico, es decir de moralista fluye con una riqueza de ingenio, de fantasía, de humor y de lirismo extraordinaria. ${ }^{10}$

\section{Este comentario choca con la afirmación de Rodríguez. Monegal:}

Un temblor mágico, un estilo personal y (a veces) delicioso, no bastan, sin duda, para hacer un gran narrador. Y Salinas no lo es, en un sentido estricto y limitado.

Con esta cita no estoy de acuerdo con que no sea un gran narrador - $\mathrm{o}$ al menos climinaría ese: «sin duda»-, pero sí en que esta afirmación de Rodríguez. Monegal se realice «en un sentido estricto y limitadom. Novelas como La música del mundo o El mundo en la era de Varick, de Andrés Ibáñe $z$, tampoco entrarían en la categoría de grandes narraciones; ni el $V$ de Pynchon ni el Meridiano de sangre de McCarthy. Se trata de narraciones postmodernas donde el conflicto causal tradicional basado en concatenación de hechos no representa la base de la narración.

Por otra, La bomba increíble: una fabulación es una obra de fuerte crítica social y humanística construida sobre muchos de los fundamentos de la ciencia ficción: la línea del género que ha sido recientemente bautizada por Julián Díez como «literatura prospectiva»" ${ }^{11}$ Con este tipo de ejemplos habrá también quien se pregunte cuál es realmente el interés literario de la obra: ¿el hecho de que la obra de Salinas es interesante por sí misma dado el innegable talento del autor o realizar una defensa del género aportando un nombre ilustre o su postmodernidad? Lógicamente, desde nuestra perspectiva de lo que es el género -una herramienta de comunicación, un proceso retórico-, lo importante es lo que se haga con dicha herramienta. Y consideramos que, con esa herramienta, Pedro Salinas escribió una obra que debe ya recuperarse en los estudios de historia de la literatura española y que sirve para entender sus ideas sin el peso ya adquirido por su obra poética, desde otro punto de vista y en consonancia con el tiempo postmoderno que estaba asentándose en su tiempo.

El poeta presenta una idea muy interesante de base: la sensación de que la sociedad se encuentra en un momento crítico por su exceso de confianza en la razón. Salinas critica la obsesión de la sociedad por dejar de lado lo pasional, lo sentimental... Y por reducirlo todo a fórmulas, orden y control de los sentimientos y de las sensaciones. Considera que la razón no puede abarcarlo todo y que existen realidades que escapan a ella. Pretendemos controlarlo todo desde la lógica y, en su opinión, cuando la lógica falle -y fallará, según se deduce de la obra-, nos encontraremos sin defensas.

¿Cómo desarrollar este primer temor postmoderno, esta impresión de la sociedad de su tiempo? En vez de acumular detalles y abundar en un realismo que pueda confundir el pensamiento

9.- Cormac McCarthy ha ganado por ejemplo, en 2007, el premio Pulitzer con una extraordinaria novela de ciencia ficción: La carretera, publicada en España por Mondadori en 2007. Bioy Casares escribió una de las mejores novelas del género y de la literatura de su país: BIOY CASARES, Adolfo (1940), La invención de Morel, Madrid: Alianza, 1999. Jorge Luis Borges ensalzó el género con frecuencia, como se ve en su prólogo a BRADBURY, Ray (1950), Crónicas marcianas, Barcelona: Minotauro, 1997. Harold Bloom cita numerosas novelas de ciencia ficción dentro de su polémico canon: BLOOM, Harold (1994). El canon occidental. Barcelona. Anagrama, 1995. Una escritora de ciencia ficción, Doris Lessing, ganó el último premio Nobel de literatura. Valgan como mínimos ejemplos de la grandeza del género más injustamente tratado por los filólogos.

10.- De nuevo, citado por A. Soria Olmedo sin referencia a la fuente, op. cit., p. 17.

11.- DÍEZ, Julián (2008), «Secesión», Hélice: reflexiones críticas sobre ficción especulativa, 10, pp. 5-11. 


\section{RECURSOS GENÉRICOS DE LA NOVELA DE CIENCIA FICCIÓN}

trascendente, universal, con la casuística de lo descrito, el poeta optó por extrapolar el problema a una sociedad que haya alcanzado el máximo de la confianza en la razón. En esta sociedad, Salinas puede incluir un elemento disruptor, irracional, que provoque el caos y contra el cual nada puede hacerse por la vía racional. La aparición de la bomba atómica, el máximo exponente de la irracionalidad creado por la Razón, constituye para él la dominante poética a partir de la cual desarrollar todo el proceso poético que sustenta la narración.

Nos encontramos con el método tradicional de la ciencia ficción de observar el mundo desde fuera.

La peor confusión que podría producirse sería la de juzgar esta fabulación como si fuera una novela del futuro, una anticipación. ${ }^{12}$

De este modo, se crea un pacto de ficción basado en la plausibilidad, que mantiene al lector en la dicotomía entre aceptar lo presentado como su propia realidad o como una exageración de la misma ${ }^{13}$. La sociedad creada por Salinas no es la de hoy, pero encontramos tal cantidad de elementos que nos recuerdan a la nuestra que la hiperbolización de nuestros defectos presentada a través de una sociedad futura nos produce la inquietud catártica buscada por Salinas.

Observemos la fábula de la novela: en esta sociedad perfecta, racional, matemática, positivista, aparece una bomba en un museo. Esta bomba no es medible ni analizable por ningún medio científico ni racional; escapa por tanto a toda posibilidad de control por parte de los ciudadanos o del Estado. Sin embargo, esta sociedad no puede aceptar que algo escape a su control intelectual, así que se esfuerza en comprenderla mediante el análisis exhaustivo. Dicho exceso de análisis provoca la activación y explosión de la bomba y, como consecuencia, la destrucción irremediable de la Humanidad.

El desarrollo de esta idea es lineal, con una inicial presentación de esta sociedad, seguida por la aparición del elemento poético disruptor y las consecuencias de dicha aparición. No encontramos una estructura posmoderna, experimental, audaz como cabría esperar de un poeta y de la época en que se escribe ${ }^{14}$. Sin embargo, a nuestro juicio, no habría servido para expresar la inquietud con la misma fuerza y habría desviado la catarsis en una dirección que no era la buscada por el autor. La estructura lineal de la novela permite una gradación cada vez más ridícula, pero también más trágica, de la situación.

Para ayudar en dicho proceso, como cabría esperar, el lenguaje se encuentra mucho más trabajado de lo que solía ser habitual en la ciencia ficción de aquellos años ${ }^{15}$.

Las resistencias del lector ante lo raro del caso deben de ser vencidas en su raíz por la naturalidad del lenguaje, que apunta brotes de popular desgarro y muestra a veces sutilísima vena arcaica e incrustaciones tópicas. $^{16}$

12.- RODRÍGUEZ MONEGAL, Emir (1976), "La obra en prosa de Pedro Salinas" en Pedro Salinas. El escritor y la crítica, Madrid: Taurus, p. 244.

13.- Algunos cjemplos muy conocidos y ortodoxos de este manera retórica de afrontar una inquietud, aparte de los ya citados, serían: Fahrenheit 451, de Ray Bradbury, o ¿Sueñan los androides con ovejas eléctricas?, de Philip K. Dick, base de la película: Blade runner.

14.- LOZANO, $\mathrm{M}^{\mathrm{a}}$ del Pilar (2007), La novela española posmoderna, Madrid: Arco/Libros.

15.- En aquel tiempo la ciencia ficción acababa de constituirse como género etiquetado, sobre nombres como: Isaac Asimov, Robert A. Heinlein o Arthur C. Clarke. La ciencia ficción más lírica haría su entrada a finales de los cincuenta y, sobre todo, durante los sesenta y setenta dentro del movimiento denominado: New Wave, con autores como Brian Aldiss, Thomas S. Disch o Samucl R. Delaney, entre otros; para un primer acercamiento a esta generación: SCHOLES, Robert y Eric S. Rabkin (1977). La ciencia ficción: historia, ciencia, perspectiva, Madrid: Taurus, 1982. pp. $101-113$.

16.- GUI.LÓN, Ricardo (1951), "Pedro Salinas, novelista", en G. DE LA CONCHA, Víctor (ed.) (1984), Barcelona: Crítica, p. 572. 


\section{FERNANDO ÁNGEL MORENO}

Resulta muy interesante en primer lugar cómo el estilo de Salinas está en perfecta consonancia con sus planteamientos temáticos. El poeta trabaja mucho con lo sugerido y aporta numerosas imágenes visuales que deben representar e incluso, aún más, simbolizar la mentalidad subyacente a la sociedad que se nos presenta: descripciones muy líricas que explican un mundo gris, numerosas preguntas retóricas, ironías y representaciones de la vida cotidiana de sus personajes, hacia una obligada identificación con nuestra propia cotidianeidad. Veremos cómo el lenguaje lírico se alterna con un discurso más frío según se desarrolle la trama y se trate un motivo u otro.

Es también creación en su ritmo, en el movimiento con que se despliega ante el ojo, el oído, del lector. Nada de monotonía, nada de calculables cadencias. Y una levedad, una inquietud, una invención de planos, para decir marcando las tensiones, para llevar la atención (el alma) pendiente de ese hilo que acaba por envolver a la realidad, envolviéndola. ${ }^{17}$

Veamos en primer lugar un ejemplo de este lenguaje sencillo, aún no en busca de un especial lirismo. En el mundo planteado por el poeta, todo es políticamente correcto; todo en esa sociedad conlleva una enseñanza y un progreso, nada existe por su mero disfrute. Podemos apreciar csta idea en la presentación del museo que soporta el peso de la mayor parte de la trama.

Solía Nicasio, en horas de poco público, arrimarse a alguna de las salas vecinas, en demanda de plática con algún compañero. Aquel día estaba de palique con un mutilado de los dos brazos (todos los guardianes del Templo de la Paz eran inválidos de guerra, para probar que si la pugna bélica deja algunas mermas las compensa con suficientes artificios y las recompensa con holgados salarios, y es por consiguiente fuente de pacíficas fruiciones) en la sala de «El alcoholismo a través de los tiempos». ${ }^{18}$

Las aportaciones al pacto de ficción para hacernos ver que se trata de una sociedad muy diferente a la nuestra aparecen a todos los niveles, pero siempre con calculadas intervenciones y sin la saturación que podría presumirse en un autor no especializado en el género. No obstante, cada una de estas apariciones aporta no sólo un elemento de atmósfera, sino una nueva aproximación a la idea presentada. En este sentido, nada en el lenguaje ni en la trama es fortuito, por lo cual lo maravilloso reside en la exageración de lo que para nosotros es natural. Por ello, más adelante sí comienzan a parecer poco pequeñas muestras de lirismo, cuando debemos escapar de las cuestiones racionales.

La policía, lidiadora tenaz con los más inferiores extremos de lo natural, las pasiones y las miserias humanas, se topaba con algo que parecía perteneciente al otro reino, al de lo sobrenatural, donde nadie ha podido tomar huellas digitales ni poner esposas a fantasmas; y el primer deber de toda policía es eliminar del horizonte pesquisitorio lo sobrenatural. ${ }^{19}$

Este pasaje no tendría nada de particular en una novela situada en nuestro tiempo y, sin embargo, aquí el pacto de ficción establecido desde el principio hace que contemplemos la función tradicional de un elemento cotidiano en una exageración propia de esta sociedad exagerada. Por supuesto que ningún policía se plantea lo sobrenatural. Y, aún así, Salinas parece indicar este hecho como un ridiculizable miedo de esta policía obsesionada con lo admisible, lo coherente, lo lógico. En este tipo de párrafos, donde lo lírico aparece en maneras tan sencillas como: «poner esposas a fantasmas» o «lidiadora tenaz con los más inferiores extremos de lo natural, las pasiones y las miserias humanas", el poeta equipara el mundo del lector con el mundo de la novela; no lo hace para fundamentar el pacto de ficción, sino para que vayamos estableciendo sucesivos puntos de unión en cuanto a nuestros referentes y los desarrollos de la novela.

A continuación se combinará el lenguaje positivista, incluso burocrático, con el lírico o con el puramente narrativo para fundamentar una poderosa ironía que impregna toda la obra.

17.- RODRÍGUEZ MONEGAL, op. cit., p. 244.

18.- SALINAS, op. cit., p. 42.

19.- Ibíd, p. 65. 


\section{RECURSOS GENÉRICOS DE LA NOVELA DE CIENCIA FICCIÓN}

Así, toda la novela es una gran ironía construida a base de pequeñas ironías; es el caso del interrogatorio del científico que ha certificado que, en un informe, no ponía «comba» sino «bomba»:

¿.Quién se fía de los sabios? Sus cabezas fértiles son trampas y añagazas armadas para que caigan en ellas los sencillos hombres de milicia. El general llamó a consejo a sus dos inferiores inmediatos. Deliberación breve y decisión unánime. Por duro que pareciese había que someter al doctor a la prueba de la ciencia, al examen del veredictógrafo, portentoso ingenio, a tal punto de perfección desarrollado, que averigua $\sin$ falla si un hombre miente o dice verdad, resolviendo de plano y con escrupulosa objetividad problemas de conducta moral que, antes, los cándidos psicólogos tenían por inexplicables. ¿Cómo un sabio iba a negarse al fallo de un aparato científico, que naturalmente figuraba en lugar lucido en el Templo de la ciencia?

Le someten a dicho sabio a la tortura de la máquina y sigue así:

El doctor respondía a todo sin titubeo. En la hoja registradora la aguja se movía, marcando con bruscos rasgos los coeficientes de veracidad del interrogado. Ya iban por los tres cuartos del experimento cuando ocurrió un flaqueo en la corriente eléctrica. Algo que no funcionaba bien. Un ayudante metió un reóforo en el cuadro. Y, de pronto, en la cabeza del doctor Viudes, brotó una llamarada azulenca, luciferina. Se retorció el cuerpo, se convulsionó, crispándose, se derrumbó inerte. Muerto. Electrocutado. ${ }^{20}$

$\mathrm{El}$ informe no resulta clarificador, si acaso bastante confuso, pero el general culpa al sabio.

Algo, o mucho, sabía. Lo mismo daba: aquel algo, o a aquel mucho ya se habían volado, espirado, de un cuerpo yacente en el depósito al que no se le podía sacar palabra mientras la ciencia, que ya lo tiene logrado casi todo, no lograse dar voz a los cadáveres. Víctima tercera: víctima de las perfidias del lenguaje que, con deslizar una c donde muy bien podía haber una b, despoja a la sociedad de un perínclito sabio y aturulla más y más el ánimo de un jefe de policía. ${ }^{21}$

Observamos los diferentes niveles de lenguaje empleados en tan escasos ejemplos y en una misma unidad de acción. Todo ello viene influenciado por la idea de base: el enfrentamiento entre lo racional y lo irracional.

En cuanto a la influencia que el género tuvo en la génesis de la obra, desconocemos los conocimientos que Salinas pudiera tener del género. Sin embargo, existen ciertas diferencias con la ciencia ficción más tradicional. El hecho de que el objeto central de la novela -la bomba increíble- carezca de posibilidad de análisis lógico choca de pleno con la idea de que la ciencia ficción presenta siempre la impresión de una verosimilitud científica para construir el pacto de ficción ${ }^{22}$. En este sentido, la obra se acercaría más a la idea que hoy se defiende como base de la teoría de la literatura fantástica en cuanto a esa «tierra de nadie» en la cual uno no sabe si se trata de un hecho fantástico o de un acontecimiento explicable por procedimientos lógicos ${ }^{23}$.

Sin embargo, la inclusión dentro de la ciencia ficción -más aún, desde la literatura prospectivase plantearía desde la idea que parece querer transmitir Salinas: un planteamiento de extrapolación plausible con la inquietud provocada por la posmodernidad de fondo. Para cllo, debe demostrar que tan real es algo incognoscible como podrían ser reales una mesa o un vaso: una experiencia

20.- Ibíd, pp. 73-74.

21.- Ibíd, p. 74.

22.- AMIS, Kingsley (1961). El universo de la ciencia ficción, Madrid: Ciencia Nueva, 1966, p. 20 y ss.

23.- Para cualquier referencia a la Teoría de la literatura fantástica, el mejor texto a día de hoy es: ROAS, David "La amenaza de lo fantástico" en ROAS, David (ed.) (2001), Teorías de lo fantástico, Madrid: Arco/L ibros, pp. 9-44. Muy interesante también, por la actualización que supone de autores contemporáneos como Stephen King o Clive Barker y de la relación del género con el cine, además de aportar otras líneas teóricas muy pertinentes, como las razones de evolución de lo fantástico: FERRERAS, Daniel F. (1995), Lo fantástico en la literatura y el cine: De Edgar A. Poe a Freddy Krueger, Madrid: VOSA, 2000. 


\section{FERNANDO ÁNGEL MORENO}

provocada al obligar a chocar dos géneros en principio antagónicos, la ciencia ficción y la literatura fantástica.

Para entender la cuestión, nos limitaremos a exponer aquí la diferencia ya consensuada entre la literatura fantástica y otras formas de literatura «anti-realista». La literatura fantástica plantea el choque intelectual que se produce en un protagonista que vive en un mundo lo más idéntico posible al del lector cuando se enfrenta a un hecho que desafía las reglas de la razón ${ }^{24}$.

Por otro lado, un factor que entra de lleno en la tradición del género y en nuestra consideración del mismo es la sociedad anti-utópica descrita por Salinas.

Por todo ello, la obra de Salinas no sólo debería analizarse como una gran obra en relación con otras novelas españolas de su tiempo, sino que además supone un experimento interesantísimo desde la teoría de los subgéneros, al romper una regla consensuada de la literatura fantástica: la fuerte relación que debe establecerse entre el mundo del lector y el mundo de la obra.

Pedro Salinas aporta a la literatura novelesca española contemporánea algo que falta -o al menos escasea mucho- en ella: una imaginación capaz de superar los linderos de lo cotidiano desplazándose a un mundo distinto y no menos real. ${ }^{25}$

El planteamiento de Salinas establece primero un sólida sociedad de ciencia ficción que ya implica en sí misma una extrapolación poética magnífica por las características ya contempladas (más las que veremos a continuación). Este punto de partida de ciencia ficción le sirve para fortalecer la introducción del choque cognitivo propio de la literatura fantástica: dos órdenes (real e irreal) en conflicto ${ }^{26}$.

De este modo, se logra un perfecto equilibrio entre la extrapolación plausible (la gran enemiga de la literatura fantástica) y la aparición de lo irracional (el gran enemigo de la literatura de ciencia ficción). Con ello, puede Salinas desarrollar su planteamiento de fondo: su inquietud ante este mundo «estúpido», como tantas veces lo adjetiva, heredado de un mal entendimiento del progreso.

Desde otro punto de vista, el procedimiento cotextual de introducción en el pacto de ficción es, de manera tradicional, muy pausado, con insistencia en la atmósfera de pensamiento de la sociedad planteada. Le interesa mucho a Salinas que el lector acepte este mundo futuro. Lo hace a partir de la arquitectura; no se trata de levantar grandes proyectos maravillosos, sino de mostrar unos edificios fríos, impersonales, acordes con la idea que quiere transmitir.

La Rotonda de la Paz, construcción armoniosa - planta circular, peristilo de columnas de bronce, y sosegada cubierta cupular-, que inspiraba con sus líneas justamente el sentir sereno de reposo que la paz despierta. ${ }^{27}$

Salinas intenta dejar cuanto antes, en el lector, la sensación de una atmósfera concreta que exprese los planteamientos de sus planteamientos iniciales. Se habla, por ejemplo, de los cañones fundidos - «inservible vestigio de unas épocas atrasadas»- para construir edificios. Todo en esta sociedad que ha creado está al servicio de lo políticamente correcto. Quiere dejar muy claro que este mundo es "perfecto» porque ha eliminado todo sentimiento, creando individuos autosuficientes fuertes y lógicos.

Y, cuando nos convencemos de la autenticidad de este mundo, lo irracional aparece poniendo tanta teoría en duda. Con ello, está funcionando el proceso de linealidad tan propio de la ciencia

24.- ROAS, op. cit., p. 9.

25.- GULLÓN, Ricardo, op. cit., p. 573.

26.- CAMPRA, Rosalba (1981), "Lo fantástico: una isotopía de la transgresión” en ROAS, David (ed.), Teorfas de lo fantástico, Madrid: Arco/Libros, 2001, pp. 153-191.

27.- SALINAS, op. cit., pp. 33-34. 


\section{RECURSOS GENÉRICOS DE LA NOVELA DE CIENCIA FICCIÓN}

ficción: dejar una impresión de seguridad para romperla con un hecho extraordinario. De este modo, se ponen en tela de juicio nuestras más firmes convicciones. Es el tipo de fórmula característica del género que aparecen en clásicos como El fin de la infancia y 2001, de odisea espacial, ambas de Arthur C. Clarke, o El hombre en el castillo, de Philip K. Dick.

Desde lo cotextual, el proceso memorístico también es evidente: dejar una seguridad muy honda en la mente del lector para que en todo momento, según avanza la trama, se perciba lo extraordinario permitiendo un contraste continuo entre lo «distópico» y lo «utópico». Pequeños recuerdos aquí y allá sirven para reforzar esta idea y no perder de vista la situación de partida. Como hemos comentado, la estructura lineal ayuda a crear este efecto.

Por ello los apuntes respecto a la sociedad van decreciendo en extensión y número, en beneficio de la trama, pero siguen apareciendo:

Con lo natural cabían transigencias, era dúctil a la técnica, y con el tiempo se lo domeñaría, como manda la Ciencia. Pero lo sobrenatural, por ser pura irracionalidad, toda inexplicable, no se merecía cuartel, ni tregua; era el enemigo a muerte. Por ello el Ministerio de Fducación había proscrito, o iba desterrando, poco a poco, las materias dañinas o contaminadas. La Historia Crítica del Arte, sustituida por la Técnica de las Artes Aplicadas; la enseñanza de la Literatura por la Técnica de la Comunicación Oral y Escrita, y así sucesivamente. Como el país era una democracia tecnológica, aún se toleraba la circulación y la lectura libre de obras de imaginación, aunque no se volvían a imprimir. ${ }^{28}$

En cuanto a la recepción de la obra, la vinculación que el lector debe hacer entre su mundo y el de creado por el autor (una de los más importantes a analizar en cada obra del género) es muy evidente ${ }^{29}$. Incluso hoy, en este año de 2008 , parece más fuerte aún y se puede descubrir con sólo estudiar los nombres de las actuales titulaciones universitarias e incluso sus planes de estudio. El poeta quiere mostrar el engaño de ese mundo que pretende tener el control sobre todo, que asume que si algo no es técnico, en consecuencia no puede ser práctico, y que sólo lo explícitamente práctico importa en el mundo. Critica esa opinión social de que la razón es suficiente para controlar la Realidad.

La ciencia ficción supone para todo cllo un vehículo magnífico.

Durante la novela, no se hace ninguna referencia a la época en la cual se sitúa la sociedad. El formato cuadra bien, sobre todo por los aparatos técnicos citados y que no existían en tiempo del autor. Por ello, cabe situarlo en el futuro y por tanto el mensaje adquiere cierta impresión de temor, de advertencia, de aviso. Por otro lado, la cercanía a nuestra propia realidad (no aparecen adelantos impresionantes que hayan cambiado todo el sistema de vida por su simple presencia, como podrían ser los viajes especiales) le permite un mayor acercamiento al lector, como hemos observado al estudiar la tipología de los posibles «tiempos» de una novela de ciencia ficción. Nuestra Realidad queda muy cercana a lo que nos cuentan y nuestra responsabilidad es real porque las consecuencias las tenemos aquí mismo, a dos pasos en el reloj.

En cuanto a los espacios, para todo lector de ciencia ficción ha de suponer una maravilla que precisamente Pedro Salinas entre en el género. Su interés por la esencia de las cosas, los objetos, la esencia de lo real... se traduce aquí en un cuidado uso de la información a través de lo material, de la descripción. Veamos con qué sentimiento plasma la forma de pensar de dos mujeres contrarias a esta sociedad fría en la cual viven:

Se acabó la misa; las dos mujeres al salir se entraron en la capilla de la Dolorosa, en la nave de la izquierda. Reinaba la imagen de talla sobre una fila de candelas encendidas y un olor de flores frescas. La

28.- Ibíd, p. 120.

29.- Pardo Pastor considera que esta relación es una de las claves de la novela, en PARDO PASTOR, op. cit., p. 137. 


\title{
FERNANDO ÁNGEL MORENO
}

cara la tenía vuelta al cielo, y en las mejillas, dos lagrimones interminables, siempre cayendo, porque no se movían. Las manos, cruzadas sobre el pecho, y encima de ellas una extraña adición que le había traído, hacía mucho, algún devoto: un gran corazón de metal dorado, que con el humo y el tiempo tenía avejentado el brillo y pasado el color; ahora todo parecía un manchón cárdeno, esperando las lágrimas de arriba, que vendrían a limpiarlo. Era imagen de la devoción de Cecilia y su madre. ${ }^{30}$

Como vemos, sustenta en los objetos mucha de la información acerca de la manera de pensar de esta sociedad, con una profunda relación simbólica entre objeto c idea. El objeto sagrado, ya gastado, consumido por el tiempo, aún guarda en sí el poder de su carga simbólica. Nos encontramos por tanto ante un cuidado discurso, consecuente con el talento de uno de los mejores poetas de la literatura española.

La bomba incréble es una iluminación del tipo de las que Salinas quiere crear en sus poemas; iluminación que explica la desesperanza presente y las razones para confiar en un renacimiento posible. ${ }^{31}$

Esta obsesión por lo espacial y su simbología encaja bien con las características genéricas estudiadas y continúa encajando si contemplamos la sencillez de los personajes: menos importantes que la idea en sí, sometidos a la fuerza del espacio creado para plasmar la idea social.

\begin{abstract}
¿Existen realmente personajes en La bomba increíble? Sroctus sensu, no. Las figuras ficticias funcionan y se mueven, pero sin personalidad, no indiferenciadas, sino someras en la individualización; arquetípicas, cada en su papel, ligada al plan a la falsilla necesaria. En esta obra se dicen muchas cosas acerca del comportamiento humano, pero no del funcionamiento de un corazón en particular. ${ }^{32}$
\end{abstract}

Apenas encontramos conflictos internos y, por ello, predomina el estereotipo. Los personajes representan meros actantes subordinados a la representación de los conflictos humanos más generales. No resulta extraño por tanto que la crítica haya pasado a menudo por alto esta interesante novela, cuando a menudo se concede mucha más importancia al conflicto interno, al personaje complejo ${ }^{33}$.

Como buen poeta, y aquí menos de acuerdo con la tradición de la ciencia ficción, el narrador está presente en todo momento de manera omnisciente. Carece de cualquier timidez para exponer juicios de valor, opiniones e incluso penetrar -como hemos visto- en los sentimientos de los personajes. Es un poeta y un ensayista: crítico con lo racional, hecho a la crítica y al ensayo de manera directa y sin intentos de ocultar su postura.

Porque en aquella elegida manera de vivir del ETC, ya lo simplemente natural, en lo que tenía de irregular y desordenado (¿es que no representa desorden que unos meses se den azucenas y otros no, que a tiempos haga frío y a tiempos calor?) y, por consiguiente, necesitado de corrección, inspiraba sospechas; y aquel punto de irracionalidad de la naturaleza, menester era someterlo a normas de razón, de suerte que hubiese azucenas todo el año, y el clima se uniformara, con una temperatura igual, de enero a diciembre. ${ }^{34}$

Tal y como ha sido presentado, La bomba increíble es una novela tan propia del género de la ciencia ficción como puedan serlo cualquiera de las citadas a lo largo de este breve análisis. Y ello se debe a que le fue útil utilizar este género para representar sus inquietudes sobre la Humanidad, recogidas en el prólogo a la edición de Viamonte:

30.- SALINAS, op. cit., 103.

31.- GULLÓN, Ricardo, op. cit.

32.- Ibíd., p. 572.

33.- Podemos encontrar estudios enteros sobre la narrativa de Salinas sin que se preste atención a esta novela, como en FEAL DEIBE, Carlos (2000), Poesía y narrativa de Pedro Salinas, Madrid: Gredos.

34.- Ibíd, p. 119. 


\section{RECURSOS GENÉRICOS DE LA NOVELA DE CIENCIA FICCIÓN}

Yo estoy convencido de que si no nos acercamos a eso que se llama el mundo del futuro, es decir a su principio, la paz, con ideas y especialmente con actitudes humanas, mucho más amplias y generosas que las de antes, estamos perdidos [...] A mí me asusta ver cómo conviven en el mismo drama, por un lado la precisión, la maravilla de organización, de capacidad ejecutiva, el progreso de la materia y sus usos inmediatos, y por otro la torpeza, la pequeñez, el egoísmo y la desorientación del pensamiento. ${ }^{35}$

\section{BIBLIOGRAFÍA CITADA}

AMIS, Kingsley (1961). El universo de la ciencia ficción. Madrid: Ciencia Nueva, 1966.

ASIMOV, Isaac (1981), Sobre la ciencia ficción, Barcelona: Edhasa, 1986.

BIOY CASARES, Adolfo (1940). La invención de Morel, Madrid: Alianza, 1999.

BLOOM, Harold (1994). El canon occidental. Barcelona: Anagrama, 1995.

CAMPRA, Rosalba (1981), "Lo fantástico: una isotopía de la transgresión” en ROAS, David (ed.), Teorías de lo fantástico, Madrid: Arco/Libros, 2001, pp. 153-191.

CLARKE, Arthur C. (1953), El fin de la infancia, Barcelona: Minotauro, 1993.

CLARKE, Arthur C. (1968), 2001, una odisea espacial, Barcelona: Plaza \& Janés, 1993.

DICK, Philip K. (1962), El hombre en el castillo, Barcelona: Minotauro, 1994.

DICK, Philip K. (1968), ¿Sueñan los androides con ovejas eléctricas? Barcelona: Edhasa, 1997.

DÍEZ, Julián (ed.), Antología de la ciencia ficción española: 1982-2002, Barcelona, Minotauro, 2003, pp. 9-29.

DÍEZ, Julián (2008), «Secesión», Hélice: reflexiones críticas sobre ficción especulativa, 10, pp. 5-11.

FEAL DEIBE, Carlos (2000), Poesía y narrativa de Pedro Salinas, Madrid: Gredos.

FERRERAS, Daniel F. (1995), Lo fantástico en la literatura y el cine: De Edgar A. Poe a Freddy Krueger, Madrid: VOSA, 2000.

FERRERAS, Juan Ignacio (1972). La novela de ciencia ficción, Madrid: Siglo XXI.

GULLÓN, Ricardo (1951), "Pedro Salinas, novelista", en G. DE LA CONCHA, Víctor (ed.) (1984), Barcelona: Crítica, pp. 570-574.

HUXLEY, Aldous (1932), Un mundo feliz, Barcelona: Plaza \& Janés, 2000.

IBÁÑEZ, Andrés (1995). La música del mundo. Barcelona: Anagrama.

IBÁÑEZ, Andrés (1999). El mundo en la era de Varick. Madrid: Siruela.

LEWIS, C.S. (2004) "Sobre la ciencia-ficción", en De este y otros mundos: Ensayos sobre literatura fantástica, Barcelona: Alba Editorial, pp. 93-110.

LOZANO, Mª del Pilar (2007), La novela española posmoderna, Madrid: Arco/Libros.

McCARTHY, Cormac (1985), Meridiano de sangre, Barcelona: Debolsillo, 2005.

McCARTHY, Cormac (2006), La carretera, Barcelona: Random House Mondadori, 2007.

MORENO SERRANO, Fernando Ángel (2007), "Notas para una historia de la ciencia ficción en España" en Dicenda. Cuadernos de Fïlología Hispánica, n² 27, pp. 125-138.

35.- Ibíd, p. 13. 


\section{FERNANDO ÁNGEL MORENO}

ORWELL, George (1949), 1984, Barcelona: Galaxia Gutenberg, 1998.

PARDO PASTOR, Jordi (2003), "La idea del 'Ser' en La bomba increíble, de Pedro Salinas" en Crítica Hispánica, vol. 25, núms. 1-2, 2003, pp. 129-147.

PYNCHON, Thomas (1963), V. Barcelona: Tusquets, 2008.

ROAS, David "La amenaza de lo fantástico", en ROAS, David (ed.) (2001), Teorías de lo fantástico, Madrid: Arco/Libros, pp. 9-44.

RODRÍGUEZ MONEGAL, Emir (1976), "La obra en prosa de Pedro Salinas" en Pedro Salinas. El escritor y la crítica, Madrid: Taurus, pp. 229-248, en particular: pp. 244-248.

SALINAS, Pedro (1950), La bomba increíble: fabulación, Buenos Aires: Editorial Sudamericana.

SALINAS, Pedro (1950), La bomba increíble: fabulación, Madrid: Aguilar, 1988.

SALINAS, Pedro (1950), La bomba increíble: fabulación, Madrid: Viamonte, 1997.

SCHOLES, Robert y Eric S. Rabkin (1977). La ciencia ficción: historia, ciencia, perspectiva, Madrid: Taurus, 1982.

TORRENTE BALLESTER, Gonzalo (1984), Quizá nos lleve el viento al infinito, Barcelona: Plaza \& Janés. 